\title{
DEVELOPMENT OF A GENERAL PRINCIPLE SOLUTION FOR ISOAGRINET COMPLIANT NETWORKING SYSTEM COMPONENTS IN ANIMAL HUSBANDRY
}

\author{
Arne Kuhlmann ${ }^{1, *}$, Daniel Herd ${ }^{1}$, Benjamin Rößler ${ }^{1}$, Eva Gallmann ${ }^{1}$, \\ Thomas Jungbluth ${ }^{1}$ \\ ${ }^{1}$ University of Hohenheim, Institute of Agricultural Engineering (440b), Garbenstr. 9, 70599 \\ Stuttgart, Germany \\ *Corresponding author, Contact: Tel.: +49(0)711459 22506; Email: arne.kuhlmann@uni- \\ hohenheim.de
}

Abstract: In pig production software and electronic systems are widely used for process control and management. Unfortunately most devices on farms are proprietary solutions and autonomically working. To unify data communication of devices in agricultural husbandry, the international standard ISOagriNET (ISO 17532:2007) was developed. It defines data formats and exchange protocols, to link up devices like climate controls, feeding systems and sensors, but also management software.

The aim of the research project, "Information and Data Collection in Livestock Systems" is to develop an ISOagriNET compliant IT system, a so called Farming Cell. It integrates all electronic components to acquire the available data and information for pig fattening. That way, an additional benefit to humans, animals and the environment regarding process control and documentation, can be generated.

Developing the Farming Cell is very complex; in detail it is very difficult and long-winded to integrate hardware and software by various vendors into an ISOagriNET compliant IT system. This ISOagriNET prototype shows as a test environment the potential of this new standard.

Key words: Data exchange, farm network, database, ISOagriNET, Farming Cell, IT FoodTrace, TINI, NSLU2

Please use the following format when citing this chapter:

Kuhlmann, A., Herd, D., Rößler, B., Gallmann, E. and Jungbluth, T., 2009, in IFIP International Federation for Information Processing, Volume 295, Computer and Computing Technologies in Agriculture II, Volume 3, eds. D. Li, Z. Chunjiang, (Boston: Springer), pp. 2011-2019. 


\section{INTRODUCTION}

Electronic systems and sensors are widely used in livestock farming. Especially in pig housing systems they are often applied to control and monitor processes. Unfortunately, most manufacturer specific solutions are working proprietary and in isolation, as they are not developed for network tasks. As a consequence, advantages like documentation and process control, arising from communication between components, remain unused.

In order to standardize data communication within farm networks, the international standard ISOagriNET (ISO 17532:2007) had been developed. Its aim is to enable the uniform communication between devices in the stable just as with external partners (Paulsen et al. 2007). On the one hand ISOagriNET defines the data formats to use. On the other hand it specifies the procedures for network based data exchange, whereby the complete process for data transmission is covered.

The essential goals of this standard are: enhancing data transmission and communication between local devices and through the internet, implementation of demand-oriented services in farm networks (Paulsen et al. 2007).

Only few products are available on the market which link up hard- and software products e.g. feeding, ventilation and management system in pig housing systems. In practice the PIG NET integrates some of these devices by using the ISOagriNET standard (Quinckhardt 2006).

\section{OBJECTIVES}

Main target of this project is to build an ISOagriNET compliant on farm network for livestock systems, called Farming Cell, which integrates existing electronic devices and software products. It serves for linking up components and collects, transmits and consolidates data for different purposes e.g. traceability of food and feed, animal welfare or environmental protection.

The Farming Cell is developed and implemented at the research station for fattening pigs, Unterer Lindenhof, at the Universität Hohenheim. The barn there consists of two separate but identical compartments, each holding 56 fattening pigs. Standard equipment is installed to operate the barn. These devices like the liquid feeding system, the ventilation system or the electronic scale are controlled by separate terminals or alternatively by software applications running on a personal computer. Beyond this standard equipment, additional sensors are installed, measuring emissions, water or energy consumption as well as activity for research purposes. 
The central task is to adapt these currently used hardware and software solutions to the international standard ISOagriNET. To harmonize nonISOagriNET compliant hardware is the main challenge. The devices need to be linked to the Ethernet and their functionality must be extended by newly developed software providing the necessary ISOagriNET functionality.

For a successful implementation companies have to be cooperative. Their software products often have to be modified or separate software interfaces for hardware components need to be programmed. The development of the Farming Cell is complex and only promising with the involvement of experts from different disciplines. For this reason the development is done in close cooperation with the manufacturers of agricultural equipment and software products.

\section{BASIC APPROACH}

The technical challenge of adapting commonly used hardware and software solutions to the ISOagriNET standard consists of two major tasks.

First of all, the present systems and sensors have to be connected to the Ethernet, as it is the transport medium defined in the standard. Secondly the features of every single component have to be evaluated and individual concepts for further development have to be elaborated.

On the one hand there are system units that are accessible via software and providing complex functionality (system units: climate and feeding control, scale with electronic ID). On the other hand, there are simple sensors just outputting a voltage or a counting impulse (sensors: water, electricity, NH3, $\mathrm{CO} 2$, etc.). These two types differ by functionality as well as hardware connectivity. While system units have standard hardware interfaces, sensors do not have these. The following chapter "Hardware Components" will go into some hardware details of the different devices.

The subsequent chapter "Software Components" deals with the second task mentioned above. In this chapter the general software concept of the Farming Cell and the differing software solutions to contact system units or sensors are described.

\subsection{Hardware Components}

This chapter explains the different device properties regarding the hardware level, which means the possibility to attach each device to the Ethernet.

There are three system units located in the research barn. 
Table 2. Hardware properties of the system units

\begin{tabular}{lll}
\hline System unit & Hardware interface & \multicolumn{1}{c}{ Ethernet connectivity } \\
\hline climate control & LON-Bus & $\begin{array}{l}\text { - No - } \\
\text { The device is controlled by a } \\
\text { computer connected via LON- } \\
\text { Bus to RS232 adapter unit }\end{array}$ \\
\hline $\begin{array}{l}\text { scale with included } \\
\text { electronic animal } \\
\text { identification (RFID) }\end{array}$ & \multirow{2}{*}{ RS232 } & $\begin{array}{l}\text { - Yes - } \\
\text { RS232 to Ethernet adapter unit }\end{array}$ \\
\hline feeding control & RS232 & $\begin{array}{l}\text { - Yes - } \\
\text { RS232 to Ethernet adapter unit }\end{array}$ \\
\hline
\end{tabular}

Table 1 shows the system units with their type of hardware interface and the way they are connected to the Ethernet.

Currently the scale and the feeding control are physically available in the Ethernet, but not accessible through software layers. Therefore they have to be invented in a next step. Further steps with regard to the climate control are unsettled so far.

Table 2. Hardware properties of sensors

\begin{tabular}{lll}
\hline Sensor & quantity & signal \\
\hline water meter & 16 & impulse \\
electric meter & 9 & impulse \\
heat meter & 2 & impulse \\
differential pressure & 1 & voltage \\
$\mathrm{NH} 3$ & 1 & voltage \\
$\mathrm{CO} 2$ & 1 & voltage \\
Temperature & 1 & voltage \\
Brightness & 1 & voltage \\
Humidity & 1 & voltage \\
\hline
\end{tabular}

All present types of simple sensors, their quantity and the signal type they output are listed in table 2 .

In contrast to the system units, simple sensors do not provide a hardware interface which is directly convertible to Ethernet. In order to link these sensors to the Ethernet, additional hardware components are necessary. Since there are no ISOagriNET compliant systems available for sensor linking, they have to be developed.

To solve this problem, the programmable and universal customizable TINI platform from Maxim, shown in figure 1, was chosen. 


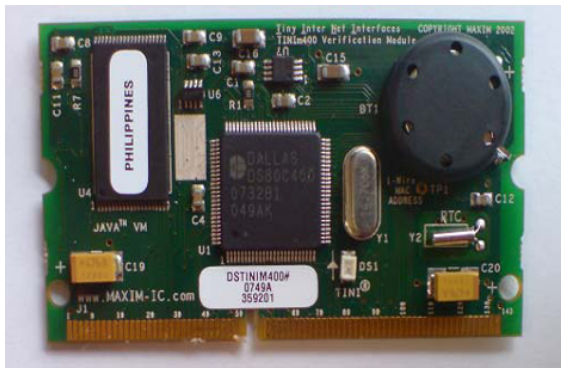

Figure 5. TINI platform

TINI (Tiny INternet Interface) is a microprocessor based platform, offering different hardware interfaces like Ethernet and One-Wire, a fully implemented TCP/IP network stack and a Java Virtual Machine 1.1.

The TINI serves as a basis for the developed One-Wire analogue/digital converter and counter modules (see Figure 2. below).
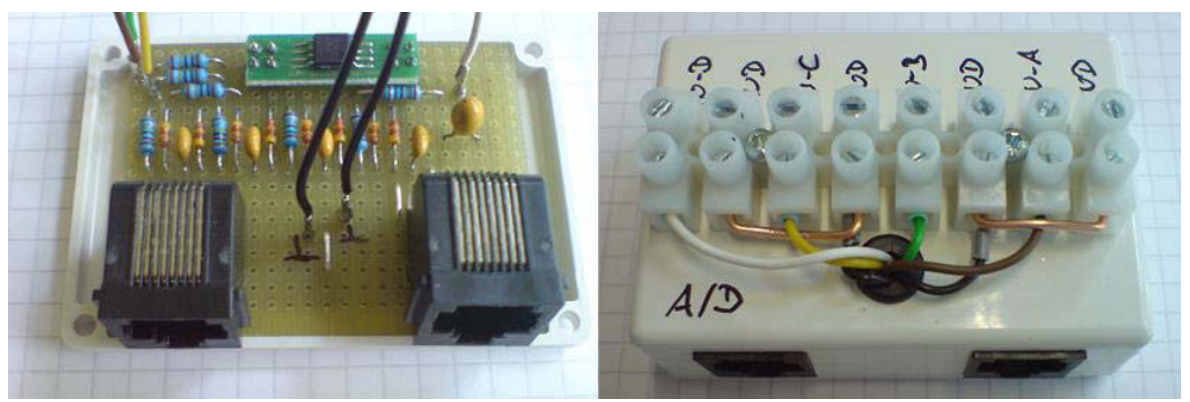

Figure 2. One-Wire A/D converter

That way both kinds of sensors, those outputting voltages and those outputting counter impulses, can be linked to the Ethernet via TINI. Beside that, each sensor connected to the TINI is configurable. The configuration of signal type, conversion formulas and other features can be performed via a web service hosted on the TINI.

The ability to connect system units and sensors to the Ethernet in the described ways leads to a complex IT-system, producing high amounts of data. This data has to be stored in a permanently available database. As a low cost and low power database server, the Network Storage Link for USB 2.0 (NSLU2) by Linksys is used (see Figure 3. below). 


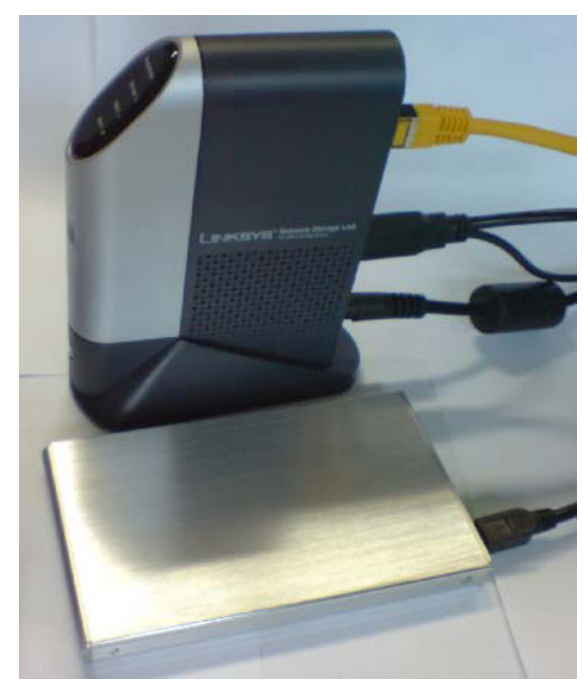

Figure 3. NSLU2 with attached 2,5" hard disk drive

The NSLU2 was originally built to connect hard disc drives as Network Attached Storage (NAS) to the local network. Due to its popularity a Debian Linux distribution for the NSLU2 is available opening up many possibilities of usage. In this case MySQL 5.0 database server was installed (compare following chapter).

\subsection{Software Components}

The previously described hardware is linked to the Ethernet, but the ISOagriNET functionality has not been implemented by software yet. Therefore individually programmed software, providing this functionality is needed. This application is written in Java and runs on the TINI platform. Sensors and system units are connected to the Ethernet via several TINI platforms hosting individual software for each type of component. The microcontrollers collect data, convert it to an ISOagriNET compliant data format and send it to a multicast group or to the originator of an enquiry.

Figure 4 shows the software concept and the way data is transmitted and collected. Within this model the Management Computer is hosting the management software for pigs which is a commercial product by agrocom $\mathrm{GmbH}$. A database is integrated in this product and stores the animal data. In addition the Management Computer will host a web server offering a web service making basic data of the farm and the pigs accessible.

In addition to the MySQL database an ISOagriNET Server was developed and installed on the NSLU2. It has three basic functions. 
$1^{\text {st }}$ it collects data send by sensors and devices.

$2^{\text {nd }}$ it holds the ISOagriNET data dictionary to convert this encoded data.

$3^{\text {rd }}$ it stores collected data in the database for sensor data.

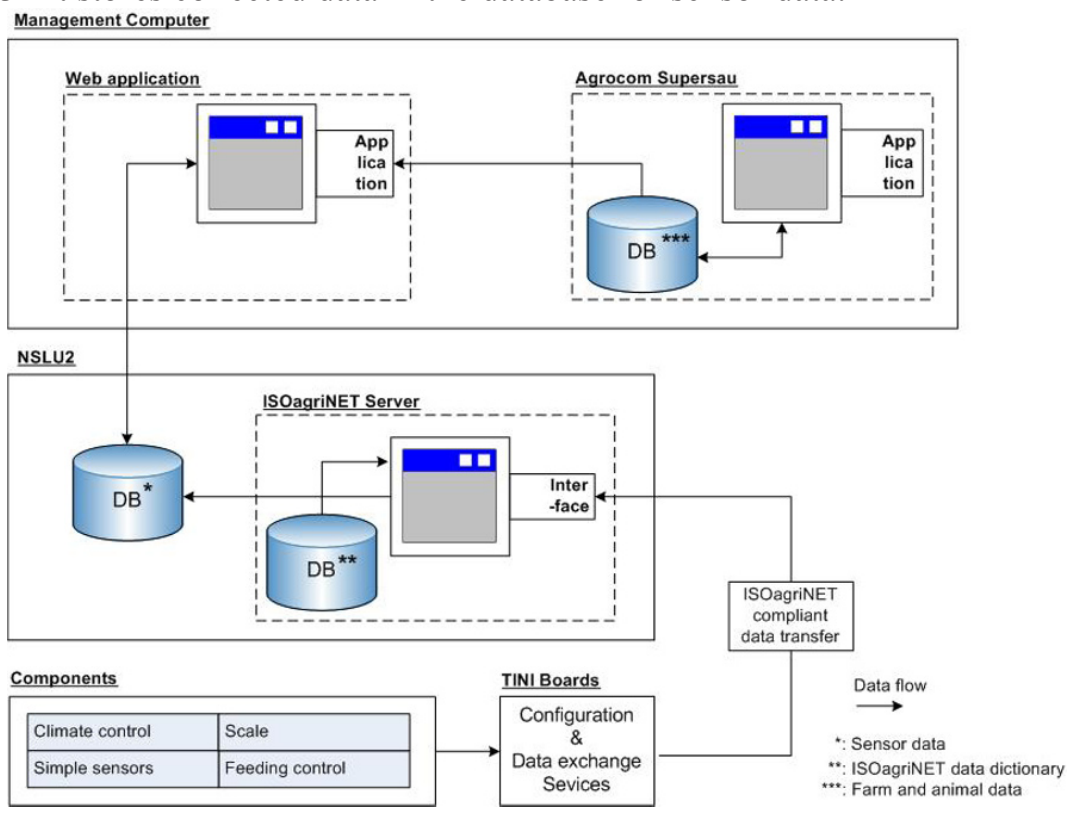

Figure4. Software Concept

The web application on the management computer to control system units has not been implemented yet.

\section{CHALLENGES}

During the implementation process there were many constraints to struggle with. The companies that are producing technical equipment for pig housing systems are using different kinds of hardware interfaces. Therefore adapters and converters to transform these interfaces to Ethernet standard are used. Software drivers were installed to transform different protocols and signals. Moreover, sensors could not be linked to the Ethernet directly, but a specific solution, the TINI board, had to be used.

The integration of many devices into the IT-system, the installation of software and in particular the development of new software has to be done individually. Therefore trained and experienced persons with very good ITskills are needed. 


\section{EVALUATION}

Many sensors and system units are under development to meet the ISOagriNET standard. Thus, they are not yet available on the market and are restraining an automated integration of devices and software into the farm network. To get around this restriction, gateways for data exchange and communication have to be created.

By knowing these potentials but also challenges there are several advantages and disadvantages for the implementation of a Farming Cell.

Advantages of the Farming Cell:

- redundant data input is avoided

- $\quad$ automation of process documentation is simplified

- availability of electronically stored data is enhanced

- data analyses for different purposes, like traceability is easy to realize

- $\quad$ work load and actual costs can be reduced

Disadvantages of the Farming Cell

- $\quad$ implementation and operation needs experts

- $\quad$ only few products which are ready for the market exist

- data security has to be guaranteed

- $\quad$ investment for hard- and software can increase

\section{CONCLUSION AND OUTLOOK}

The implementation of an over all IT-system by linking up individual hard- and software components produced by different manufacturers is very complex, mainly due to incompatibility. There is still a lot industrial effort needed to standardize on farm equipment. New open source gateways or standards are on the way. Companies and administrative bodies are supporting the development.

Process documentation in pig housing systems has not to be done electronically. But there are advantages for this, e.g. improved speed and effectiveness for data analysis. Thus, central database or management systems will become more important. On the other side, the implementation and operation of these complex IT-systems need experts with hard- and software skills.

This project with its ISOagriNET prototype will help to evaluate the benefits and drawbacks of the standard. Further it contributes to the implementation of standards within a heterogeneous hard- and software world. 
Development of a General Principle Solution for Isoagrinet Compliant 2019 Networking System Components in Animal Husbandry

\section{ACKNOWLEDGEMENTS}

The research project „Information and Data Collection in Livestock Systems" is part of the "Federal Ministry of Education and Research" project „IT FoodTrace“ (maturity June 2006 till May 2009), www.itfoodtrace.de.

\section{REFERENCES}

ISO 17532 - INTERNATIONAL ORGANIZATION FOR STANDARDIZATION: ISO 17532:2007 - Stationary equipment for agriculture - Data communications network for livestock farming, CH Geneva.

Paulsen, C.; Martini, D.; Kunisch, M., 2007: Austausch von Daten aus der Tierhaltung mit agroXML - Konzeption der Zusammenarbeit mit ISOagriNET: p. 97 - 104. In: KTBLSchrift 454: agroXML - Informationstechnik für die zukunftsorientierte Landwirtschaft. KTBL - Vortragstagung vom 17. bis 18. April 2007 in München, Germany. Darmstadt, Germany.

Quinckhardt, M., 2006: Vernetzte Managementhilfen zur Steuerung und Dokumentation von Prozessabläufen in der Tierhaltung: p. 119 - 124. In: VDI-Bericht Nr. 1935, 2006: Tagung Tier Technik 2006, Lebensmittel aus dem Stall. Stuttgart, Düsseldorf, Germany 